\title{
Psychosocial Health Status of Patients Diagnosed with Chronic Illnesses in Jordan
}

\author{
Dana D. Al Abeiat1', Ayman M. Hamdan-Mansour',3, Bushra Mustafa Ghannam³, \\ Saleh N. Azzeghaiby', Laila Y. Dawood ${ }^{5}$ \\ ${ }^{1}$ Specialty Hospital, Amman, Jordan \\ ${ }^{2}$ Department of Community Health Nursing, Al-Farabi College, Riyadh, KSA \\ ${ }^{3}$ Faculty of Nursing, The University of Jordan, Amman, Jordan \\ ${ }^{4}$ Al-Farabi College, Riyadh, KSA \\ ${ }^{5}$ Department of Clinical Nursing, Faculty of Nursing, University of Jordan, Amman, Jordan \\ Email: ddawod89@yahoo.com, a.mansour@ju.edu.jo, Bushra_ghannam@yahoo.com, talal5656@yahoo.com, \\ Idawood2012@gmail.com
}

Received 10 April 2014; revised 10 May 2014; accepted 10 June 2014

Copyright ( 2014 by authors and Scientific Research Publishing Inc.

This work is licensed under the Creative Commons Attribution International License (CC BY).

http://creativecommons.org/licenses/by/4.0/

(c) () Open Access

\section{Abstract}

Background: The comorbidity between chronic physical conditions and psychosocial health consequences is becoming a research interest for researchers in the field. The purpose of this study was to investigate the psychosocial health status of patients diagnosed with chronic illnesses in Jordan. Methods: A cross sectional survey using 806 patients diagnosed with chronic illnesses has been used to collect data in regards to depressive symptoms, psychological distress, coping, optimism, life satisfaction, and perceive social support. Results: $17.5 \%$ of the patients reported that they had moderate to severe depressive symptoms, and about $50 \%$ of them had high level of optimism and life satisfaction, moderate level of effectiveness of coping skills, psychological distress, and perceived social support from family, friends and others. There were significant association between patients' age and their scores on perception of social support from family, friends and others, life satisfaction, and psychological distress $(p>0.05)$. While, male and female patients were different in their depressive symptoms $(t=-2.57, p=0.01)$, perceived social support from others $(t=-2.06, p=0.04)$, and optimism $(t=2.29, p=0.02)$. Also, patients had differences in their depressive symptoms, perceived social support from friends, others and friends, optimism, life satisfaction, and psychological distress related to their medical diagnoses $(p<0.05)$. Conclusion: Patients with chronic illness are in need for psychological care, and periodic psychological screening is one step toward maintaining their psychological wellbeing. 


\section{Keywords}

\section{Psychosocial Health, Chronic Illnesses, Jordan}

\section{Introduction}

Chronic diseases have assumed an increasingly important role in reforming health research and interventions. Therefore, comorbidity between chronic physical conditions and psychosocial health consequences such as depressive feelings, stress, adherence, and psychosocial health concerns became common interest for health professional and researchers. According to Doumit and Nasser [1], patients with chronic illnesses are overwhelmed with psychological stressors due to requirement related to management of their illnesses. However, patients' psychosocial status may interfere with their ability to manage their needs independently that may exacerbate their health condition [2]. For example, patients with chronic illnesses may suffer unexplained symptoms, anxiety and depressive feelings that delay their recovery and healing process [3] [4]. Thus, patients with chronic illnesses are struggling to manage their physical illnesses independently and further overwhelmed with vulnerability to increased psychosocial co-morbidity [2].

The comorbidity of psychological problems with chronic illnesses raised the issue of the impact of psychological disturbances on patients' health condition. The literature showed that the psychological difficulties and psychological follow up care have been linked with increased morbidity, mortality, and expenditure of health services [5] [6]. Health care professional may sacrifice psychological care and focus only on patients' physiological needs. This will negatively influence the disease prognosis resulting in poor treatment outcomes and may increase mortality rate [7] [8]. The impact of chronic illnesses on the bio-psycho-social aspects of individual's health and wellbeing cannot be interpreted solely in terms of disease process, but also relates to difficulties of individuals' adjustment to their illnesses and the evolved changes of their lifestyle [9] [10]. Therefore, issues, for example, related to coping, social support, stress, optimism, and life satisfaction are significant in process of health-illness continuum. Number of previous studies showed that there is a strong relationship between difficulties in coping mechanisms, perceived social support and the development of anxiety and depression among patients with chronic illnesses [11]. Indeed, the ability of patients to adjust and control their life stressors is associated with better psychosocial wellbeing [11].

The issue of management of chronic illnesses has showed growing interest for policy makers in the Arabian region and particularly in Jordan. However, the information related to psychological status of patient with chronic illnesses is limited. There is a need to explore the psychological and social wellbeing of those patients especially with the increased cost and demands for health care services globally. This study came to respond to these concerns and more to increase our knowledge in the field of mental and psychological wellbeing of patient with chronic illnesses. Therefore, the purpose of this study is to investigate the psychosocial health status of patients with chronic illnesses in Jordan. The specific aims are:

- To determine the psychosocial health status of patients with chronic illnesses in Jordan in regard to related to stress, depression, perceived social support, coping, optimism, and life satisfaction.

- The difference of the identification is the psychosocial health status of patients with chronic illnesses in Jordan in relation to selected demographic and personal characteristics of age, gender, working status, and medical diagnosis.

\section{Method}

\subsection{Design}

A quantitative approach using cross-sectional, descriptive-correlational design was used to examine the psychosocial health status of patients with chronic illnesses in Jordan. Data was collected from patients diagnosed with diabetes mellitus-type-II, Rheumatoid arthritis, CAD, cancer, and pulmonary diseases from the three health care sectors in Jordan (governmental, educational and private). Information collected in regards to stress, depression, perceived social support, coping, optimism, and life satisfaction. 


\subsection{Sample and Settings}

Patients diagnosed with diabetes mellitus-type-II, Rheumatoid arthritis, CAD, cancer, and pulmonary diseases represented the population for this study. A convenience sampling of 806 completed and retuned the questionnaire. The study targeted patients attending primary, secondary and tertiary care units. Inclusion criteria include: 1) diagnosed with one of the following chronic illness for longer than 6 months: diabetes mellitus-type-II, rheumatoid arthritis, CAD, cancer, and pulmonary diseases, 2) at age of 18 years or older, and 3) ability to read and write in Arabic. Exclusion criteria included: no history of diagnosed mental or cognitive disorders.

\subsection{Data Collection Procedure}

Prior data collection, ethical approval obtained from the Faculty of Nursing at the University of Jordan, and the targeted institutions. Data collected using self report format. Patients who expressed interest to participation in the study were approached by the researcher who explained the study and provided them with all details and answered all their questions. Patients were asked to sign the consent letter that included information related to the title of the study, its purpose, its significance and a statement informing the participants that their privacy would be protected by assuring them that their responses will be treated confidentially, and information that reveal their identity will not be recorded. Also, they were assured that the information will be used for the purpose of the study, and that their participation is voluntary and they have the right to withdraw at any time during the study and that their decision will not influence the quality of care they receive. The whole package presented in Arabic language.

\subsection{Instruments}

The data collected using an Arabic version of self-reporting questionnaires. The tools first translation into Arabic language by a research assistant and back translated into English language another independent research assistant as described by Brislin [12]. Pilot testing conducted using patients $(n=25)$ requesting their appraisals for the appropriateness of the translation.

The Instruments were:

1. Perceived social support was measured by Multidimensional Scale of Perceived Social Support [13]. This scale is 12-item self-reported scale to assess the perception of social support adequacy from the family, friends, and significant others such as health care team. Each item is measured using a 7-point Likert scale ranging from 1 (very strongly disagree) to 7 (very strongly agree). The higher the score is the higher the perceived social support. This scale had good internal consistency for the scale as whole which was 0.88 . In this study, Cronbach's Alpha for the subscales were 0.85 (Family), 0.79 (friends), and 0.75 (others).

2. The Beck Depression Inventory-II (BDI-II) [14] was used to assess patients' depressive symptoms, which contain items that measure cognitive-affective symptoms and attitudes, impaired performance, and somatic symptoms [14]. This instrument contains 21 questions answered on a four-point Likert scale in which 0 represents the absence of symptoms and 3 represents an extreme problem. The total range of 0 to 63 and standard cutoff points as follow: 0 - 13 indicates no or minimal symptom, 14 - 19 indicates mild symptoms, 20 - 28 indicates moderate symptoms, and 29 - 63 indicates severe symptoms [14]. A score of 13 is the cutoff point indicating depression. The test-retest $r$ was .88, and Cronbach's Alpha is 0.87 [14]. In this study, Cronbach's Alpha was 0.85 .

3. Stress was measured using the brief form of Psychological Stress Measure [15]. The original Psychological Stress Measure (PSM) was designed using 49 items drawn from descriptors generated by focus groups on stress. The scale is unifactorial in structure and maintains a test-retest stability of 0.68 to 0.80 under apparently constant conditions. Patients checks the answer that best indicates the degree to which each statement has applied to him/her recently The responses made on a Likert scale and ranged from range from 1 (null) to 4 (much). The higher the score in the scale reflect higher level of psychological stress. In this study, Cronbach's Alpha was 0.88 .

4. Coping skills was measured using the abbreviated version of the COPE Inventory [16]. Brief COPE is a 28 items scale measures the ways individuals use to cope with stress in their life. Brief COPE is formed of 14 domains (each consisted of 2 items) were responses ranged from 1 (I haven't been doing this at all) to 4 (I've been doing this a lot). The scale takes $>10$ minutes to be completed. The scale has good internal inconsistency with Cronbach's alpha of 0.83 (Carver, 1990). In this study, Cronbach’s Alpha was 0.73. 
5. Optimism was measured using the Life Orientation Test (LOT-R) [17]. The LOT-R is designed to measure optimisms by assessing the generalized outcome expectancies of individuals. Each item is scaled on a five point Likert scale. The responses ranges from strongly agree to strongly disagree. The scoring is done by reversing the negative statement and then adding all the responses together. Cronbach's alpha for the scale was 0.76 and test-retest was estimated at 0.79 [17]. In this study, Cronbach's Alpha was 0.81 .

6. Life satisfaction was measured using the Satisfaction with Life Scale [18]. This is a general measure of life satisfaction, which consisted of five statements. Participants were asked to rate each statement according to the following seven-point scale: 1) strongly disagree, 2) disagree, 3) slightly disagree, 4) neither agree nor disagree, 5) slightly agree, 6) agree, and 7) strongly agree. The scores of the total scale ranges from 5 to 35 and interpreted as follow: from 31 - 35 (eextremely satisfied), from 26 - 30 (satisfied), from 21 - 25 (slightly satisfied), 20 (neutral), from 15 - 19 (slightly dissatisfied), from 10 - 14 (dissatisfied), and 5 - 9 (extremely dissatisfied). The test-retest reliability was estimated to be 0.87 [18]. In this study, Cronbach's Alpha was 0.78 .

\subsection{Potential Covariates}

Gender, age, marital status, type of disease, duration of disease, smoking status, income, Education level and work status. The demographic information obtained from an investigator-developed subject profile.

\section{Results}

\subsection{Descriptive Characteristics}

A total number of 806 patients completed the questionnaire (see Table 1). Patients' age ranged from 18 to 90 years, with mean of $51.5(S D=15)$. About $54 \%(n=436)$ of the patients there were male patients, while $45.9 \%$

\section{Table 1. Descriptive characteristics of patients diagnosed with chronic illnesses $(n=806)$.}

\begin{tabular}{|c|c|c|c|c|c|c|c|c|}
\hline \multicolumn{2}{|c|}{ Variable } & $\mathrm{n}$ & $\%$ & M & SD & Md. & $\mathrm{P}_{25}$ & $\mathrm{P}_{75}$ \\
\hline \multicolumn{2}{|c|}{ Age } & & & 51.5 & 15 & 52 & 41.8 & 63 \\
\hline \multirow{2}{*}{ Gender } & Male & 436 & 54.1 & & & & & \\
\hline & Female & 370 & 45.9 & & & & & \\
\hline \multirow[t]{5}{*}{ Marital status } & Single & 85 & 10.5 & & & & & \\
\hline & Married & 595 & 73.8 & & & & & \\
\hline & Widow & 84 & 10.4 & & & & & \\
\hline & Divorced & 42 & 5.2 & & & & & \\
\hline & Not working & 419 & 52 & & & & & \\
\hline \multirow[t]{4}{*}{ Working status } & Part-time job & 60 & 7.4 & & & & & \\
\hline & Full time job & 204 & 25.3 & & & & & \\
\hline & >High school & 365 & 45.3 & & & & & \\
\hline & High school & 171 & 21.2 & & & & & \\
\hline \multirow[t]{5}{*}{ Level of education } & Diploma & 120 & 14.9 & & & & & \\
\hline & Bachelor & 127 & 15.8 & & & & & \\
\hline & Graduate & 4 & 0.5 & & & & & \\
\hline & Diabetes mellitus & 230 & 28.6 & & & & & \\
\hline & Cardiovascular & 174 & 21.6 & & & & & \\
\hline \multirow[t]{3}{*}{ Medical diagnoses } & Pulmonary & 118 & 14.6 & & & & & \\
\hline & Cancer & 92 & 11.4 & & & & & \\
\hline & Rheumatoid Arthritis & 107 & 13.3 & & & & & \\
\hline \multirow[t]{2}{*}{ Smoking } & Smoking & 241 & 9.9 & & & & & \\
\hline & Not smoking & 565 & 70.1 & & & & & \\
\hline
\end{tabular}


$(\mathrm{n}=370)$ were females. In regard to marital status, the majority of them $73.8 \%(\mathrm{n}=595)$ were married, while $5.2 \%(n=42)$ were divorced, and $10.5 \%(n=85)$ were single, and $10.4 \%(n=84)$ were widow. The analysis also showed that most of patients $(52 \%, n=419)$ were not working, and $25.3 \%(n=204)$ of them had a full time work, also $15.3 \%(n=123)$ had retired, where the least percent $7.4 \%(n=60)$ of patients had a part time work.

In regard to their medical diagnosis, the analysis showed that $28.6 \%(n=230)$ of the patients had diabetes mellitus type-II, $21.6 \%(n=174)$ had cardiovascular disease, $14.6 \%(n=118)$ had pulmonary diseases, $13.3 \%$ $(\mathrm{n}=107)$ had rheumatoid arthritis, and $11.4 \%(\mathrm{n}=92)$ had cancer. The analysis also showed that the majority (70.1\%, $n=565)$ of patients were not smoking, while $29.9 \%(n=241)$ were active smokers. Among those who smoke, $25 \%(n=60)$ of them smoked more than 10 cigarettes per day.

\subsection{Psychosocial Health Status}

\subsubsection{Depression}

Regarding depressive symptoms, the analysis (see Table 2) showed that the patients had a mean score of 16.1 $(\mathrm{SD}=10.2)$ with scores ranging from 0 to 54 . About $50 \%$ of the patients had a score of 16 or above. In regards to level of depression, the analysis showed that $41.4 \%(n=334)$ of the patients found to have no or minimal depressive symptoms, while $31 \%(\mathrm{n}=250)$ had mild depressive symptoms, $15.5 \%(\mathrm{n}=125)$ had moderate depressive symptoms, and $12.0 \%(\mathrm{n}=97)$ had severe depressive symptoms. The analysis indicates that about $25 \%$ of the patients are suffering from depressive symptoms compared to $41 \%$ with no to minimal depressive symptom.

\subsubsection{Optimisms}

Regarding patients' optimism perception using life orientation scale (see Table 2), the analysis showed that patients had a mean score of 34.5 ( $\mathrm{SD}=5.9$ ) with scores ranging from 10 to 50 . Considering that the possible range of score is 5 - 50, and that the analysis showed that $50 \%(n=403)$ of the patients had a score of 34 or above and $50 \%$ of them had a score between 32 and 38, the results indicate that patients, in general, had high level of optimism.

\subsubsection{Coping Skills}

Regarding patients' coping skills using brief COPE scale (see Table 2), the analysis showed that patients had a mean score of $71.6(\mathrm{SD}=10.1$ ) with scores ranging from 29 to 104. Considering that the possible range of score is 28 - 112, and that the analysis showed that $50 \%(n=403)$ of the patients had a score of 71 or above and $50 \%$ of them had a score between 67 and 77, the results indicate that patients, in general, had moderate of their ability to effectively cope with their life situations.

\subsubsection{Life Satisfaction}

Regarding patients' satisfaction about their life (see Table 2), the analysis showed that patients had a mean score of 23.8 ( $\mathrm{SD}=5.8$ ) with scores ranging from 5 to 35. Considering that the possible range of score is 5 - 35, and that the analysis showed that $50 \%(n=403)$ of the patients had a score of 25 or above and $50 \%$ of them had

Table 2. Psychosocial health status of patients diagnosed with chronic illness in Jordan $(n=806)$.

\begin{tabular}{|c|c|c|c|c|c|c|c|c|}
\hline Variable & $\mathrm{n}$ & $\mathrm{M}$ & SD & Min & Max & $\mathrm{P}_{25}$ & $\mathrm{P}_{50}$ & $\mathrm{P}_{75}$ \\
\hline Depressive symptoms & 806 & 16.1 & 10.2 & 0 & 54 & 9 & 16 & 21 \\
\hline Social support-other & 806 & 22.7 & 4.9 & 4 & 28 & 21 & 24 & 26 \\
\hline Social support-family & 806 & 22.2 & 4.8 & 4 & 28 & 20 & 23 & 26 \\
\hline Social support-friends & 806 & 18.4 & 6.2 & 4 & 28 & 14 & 20 & 23 \\
\hline Optimism & 806 & 34.5 & 5.9 & 10 & 50 & 32 & 34 & 38 \\
\hline Life satisfaction & 806 & 23.8 & 5.8 & 5 & 35 & 21 & 25 & 28 \\
\hline Coping & 806 & 71.6 & 10.1 & 29 & 104 & 67 & 71 & 77 \\
\hline Psychological distress & 806 & 41.9 & 11.3 & 14 & 68 & 33 & 42 & 51 \\
\hline
\end{tabular}


a score between 21and 28, the results indicate that patients, in general, had high level of satisfaction about their life.

\subsection{Psychological Distress}

Regarding patients' psychological distress level (see Table 2), the analysis showed that patients had a mean score of $41.9(\mathrm{SD}=11.7)$ with scores ranging from 14 to 68 . Considering that the possible range of score is 9 72 , and that the analysis showed that that $50 \%(n=403)$ of the patients had a score of 42 or above and $50 \%$ of them had a score between 33 and 51, the results indicate that patients, in general, had moderate level of stress.

\subsection{Perceived Social Support}

Regarding patients' perception of perceived social support (see Table 2), the analysis showed that patients' highest perception of perceived social support was from others and family with mean scores of 22.7 (SD = 4.9) and $22.2(\mathrm{SD}=4.8)$ respectively. However, patients had lower perception of social support from friends with score of 18.4 (SD = 6.2). In general, perception of social support from family, friends and other were at the moderate level give the possible range of score for each subscale to be $4-28$ and the median scores for all subscales were almost equal and at the moderate to high level (23 - 26). The analysis is showing the lowest level of perception was support from friends although the scores of seem to be at the moderate level.

\subsection{Differences in Psychological Factors Related to Demographic Characteristics}

Regarding the relationship between selected demographic characteristic and psychosocial factors, the analysis showed that there was a significant and positive correlation between patients' age and their perception of social support from family $(r=0.11, p=0.003)$ and others $(r=0.08, p=0.04)$, and life satisfaction $(r=0.14, p<$ 0.001 ).while, there was a significant and negative correlation between patient's age and perceived social support from friends $(\mathrm{r}=-0.10, \mathrm{p}=0.004)$ and psychological distress $(\mathrm{r}=-0.08, \mathrm{p}=0.03)$. The results indicate that that older patients are more likely to have higher level of support from friends and others, and life satisfaction, and lower level of support from friends and higher level of psychological distress.

Regarding gender differences, the analysis showed that there was significant difference between male and female patients in their depressive symptoms $(\mathrm{t}=-2.57, \mathrm{p}=0.01)$, perceived social support from others $(\mathrm{t}=$ $-2.06, p=0.04)$, and optimism $(t=2.29, p=0.02)$. The analysis also showed that female patients higher score on BDI and perception of social support from others, and lower scores in optimism than male patients.

To examine the differences in psychological factors in relation to working status, one-way ANOVA was conducted. The analysis showed that there was a significant difference in depressive symptoms, and perceived social supports from family in regards to working status, $\left(\mathrm{F}_{3,806}=9.3\right.$, $\mathrm{p}<0.05, \mathrm{~F}_{3,806}=3.1, \mathrm{p}<0.05$, respectively). Using post hoc comparison (scheffe), the analysis showed that that those who are not working $(\mathrm{M}=17.8$, $\mathrm{SD}=10.5$ ) were significantly different (higher mean) in their BDI score from those working full time $(M=13.5$, $\mathrm{SD}=8.9)$. Also those who are not working $(\mathrm{M}=22.5, \mathrm{SD}=5.1)$ were significantly different (higher mean) in their perception of social support from family those who had part-time job $(M=20.6, S D=5.0)$. Regarding the other factors than include perceived social support from others and friends, optimism, life satisfaction, coping and psychological distress, the analysis showed that there are no differences between patients scores related to their working status $(\mathrm{p}>0.05)$.

\subsection{Differences in Psychosocial Factors Related to Medical Diagnosis}

To examine the differences in psychological factors in relation to patients' medical diagnoses, one-way ANOVA was conducted. The analysis (see Table 3) showed that there were significant differences related to medical diagnoses in depressive symptoms, perceived social support from friends, others and friends, optimism, life satisfaction, and psychological distress. Regarding depressive symptoms $\left(\mathrm{F}_{5,806}=12.8, \mathrm{p}<0.05\right)$, and using post hoc comparison (Scheffe), the analysis showed that patients diagnosed with cancer are significantly different (had higher mean score) $(\mathrm{M}=21.9, \mathrm{SD}=12)$ from all other patients; pulmonary disease $(\mathrm{M}=14.9, \mathrm{SD}=9.9)$, CVD $(\mathrm{M}=15.9, \mathrm{SD}=10.6)$, RA $(\mathrm{M}=15.9, \mathrm{SD}=10.2)$, and $\mathrm{DM}-\mathrm{II}(\mathrm{M}=13, \mathrm{SD}=8.4)$. The results indicate that patients diagnosed with cancer had more depressive symptoms than all other patients diagnosed with chronic illness in this study. Moreover, regarding the perceiving social support from others $\left(F_{5,806}=3.4, p<0.05\right)$, post 
Table 3. Difference in psychosocial factors of patients diagnosed with chronic illnesses in Jordan related to medical diagnosis $(n=806)$.

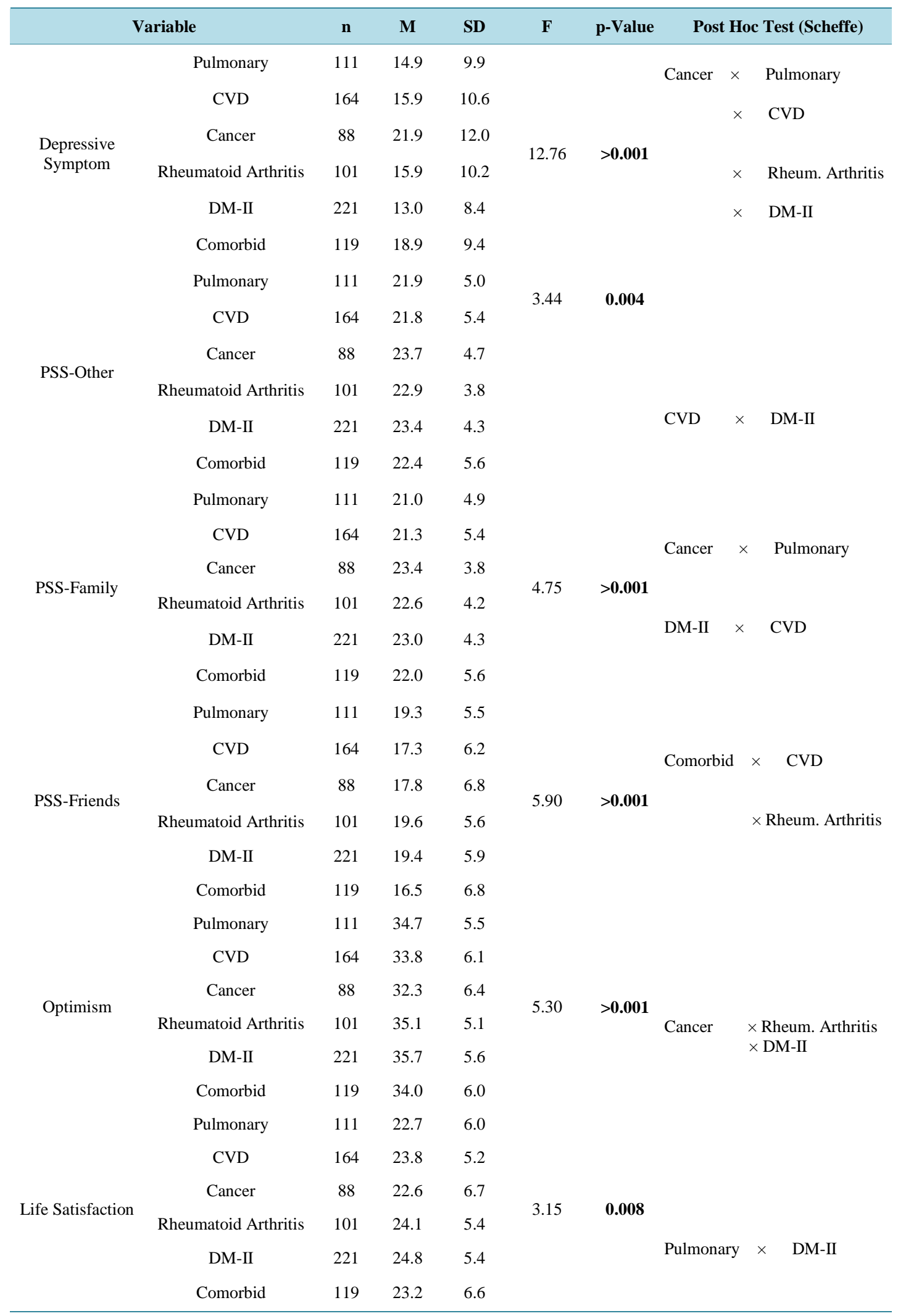




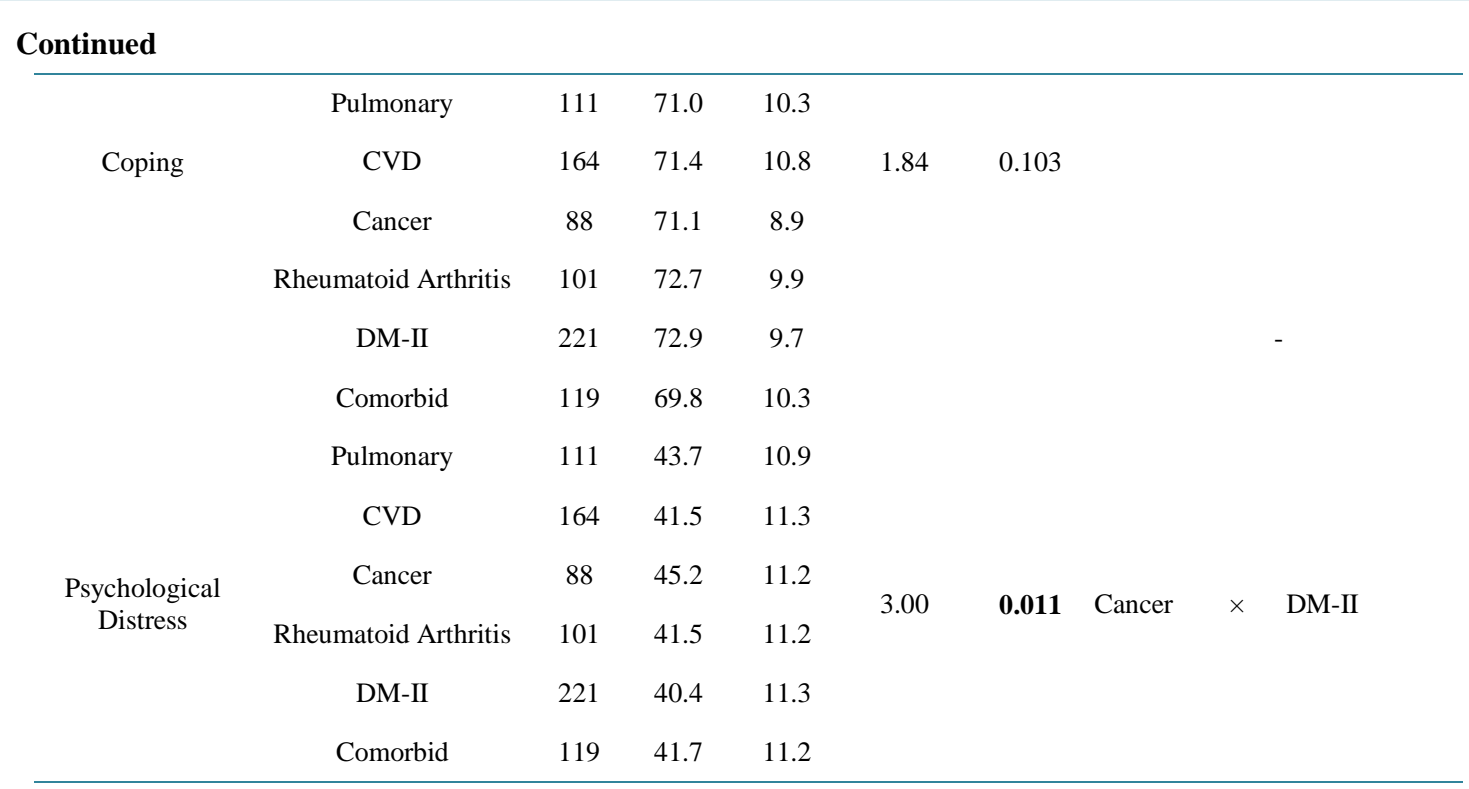

hoc comparison showed that patients who are diagnosed with CVD $(M=21.8, S D=5.4)$ are significantly different (lower mean score of perception) from those diagnosed with DM-II $(M=23.4$, SD $=4.3)$. Related to perceived social support from family $\left(\mathrm{F}_{5,806}=4.6, \mathrm{p}<0.05\right)$, post hoc comparison showed that patients who are diagnosed with cancer $(\mathrm{M}=23.4, \mathrm{SD}=3.8)$ are significantly different (higher mean score of perception) that patients diagnosed with pulmonary disease $(\mathrm{M}=21, \mathrm{SD}=4.9)$, and patients diagnosed with $\mathrm{DM}-\mathrm{II}(\mathrm{M}=23, \mathrm{SD}=$ 4.3) are significantly different (higher mean score of perception) that patients diagnosed with CVD $(\mathrm{M}=21.3$, $\mathrm{SD}=5.4)$. Related to perceived social support from friends $\left(\mathrm{F}_{5,806}=5.9, \mathrm{p}<0.05\right)$, post hoc analysis revealed that people with co-morbid diseases $(M=16.5, S D=6.8$ ) are significantly different (lower mean score of perception) from those diagnosed with CVD $(M=17.3, S D=6.2)$, and RA $(M=19.6, S D=5.6)$. This indicates that patients who are suffering from more than one chronic disease had lower perception, in general, than those who are diagnosed with one chronic illness. In regard to optimism, the analysis also revealed significant differences between patients related to their medical diagnosis $\left(\mathrm{F}_{5,806}=5.3, \mathrm{p}<0.05\right)$. Post hoc test showed that patients diagnosed with cancer $(\mathrm{M}=32.3, \mathrm{SD}=6.4)$ are significantly different (had lower mean score of optimism) from those diagnosed with RA $(M=35.1, \mathrm{SD}=5.1)$ and DM-II $(M=35.7, \mathrm{SD}=5.6)$. Regarding life satisfaction, the significant differences $\left(\mathrm{F}_{5,806}=3.2, \mathrm{p}<0.05\right)$, using post hoc comparison, was between those diagnosed with pulmonary disease $(\mathrm{M}=22.7, \mathrm{SD}=6.0)$ and those diagnosed with $\mathrm{DM}-\mathrm{II}(\mathrm{M}=24.8, \mathrm{SD}=5.4)$, with means score of life satisfaction higher among those diagnosed with DM-II. In relation to the significant difference between patients related to psychological distress $\left(F_{5,806}=3.0, p<0.05\right)$, the analysis, using post hoc comparison, was between those diagnosed between those diagnosed with cancer $(M=45.2, S D=11.2)$ and those with DM-II (M = 40.4, SD = 11.3), with means score of psychological distress of patients diagnosed with cancer higher than those diagnosed with DM-II.

\section{Discussion}

Physical health conditions may produce psychological disturbances, and psychological problems may exacerbate physical condition of individuals diagnosed with chronic illnesses [1] [19]. Therefore; screening for psychological factors among patients diagnosed with chronic illness/s, is considered a primary function for health professional caring for this group of patients [20]-[22]. This study aimed at examining the psychological and social health factors among patients diagnosed with chronic illnesses in Jordan. The study found, in general, that patients diagnosed with chronic illnesses in Jordan suffer psychological and social disturbances. A significant number of patients (17.5\%) reported having moderate to severe depressive symptoms, and about $50 \%$ of them had high level of optimism and life satisfaction, and moderate level of effectiveness of coping skills, psychological distress, and perceived social support from family, friends and others.

Previous international studies aimed at detecting prevalence of psychological disturbances among patients 
with chronic illness were controversial. While some studies [23] [24] found that depression was common among patients with chronic illnesses and that incidence of depression is almost twice among patients with diabetes mellitus, others [25] reported that depressive symptoms was less prevalent among patients with chronic illnesses than those with acute illnesses. Moreover, other studies found that chronic illnesses increased the vulnerability to psychological stressors and psychosocial co-morbidity [1] [19]. The results of our study do support those who found that depressive symptoms are prevalent among patients with chronic illnesses. However, we have found also that patients were almost optimistic, use effective coping skills more frequently, and had positive perception of social support. The results contrast previous reports and add a new understanding to the intercorrelation between psychosocial factors among patients with chronic illnesses. One possible explanation is that patients had depressive feeling, however; they have also utilized available sources of social support and used effective coping skills that might enabled them to effectively manage these negative symptoms. Another explanation might be related to the intercorrelation of depressive symptoms and psychological distress and the use of social support as buffering system. According to Cohen, Gottlieb and Underwood [26], social support influences health through either the stress-buffering model or the main effect model. The main premises of the stress-buffering model is that others will provide necessary resources that may redefine the potential for harm posed by a situation and cushions one's perceived ability to cope with imposed demands, thereby preventing a particular situation from being perceived as stressful. Supportive beliefs may reduce maladaptive behaviors. In addition, the main-effect model claims that the individual is under the influence of social control [26]. These two models provide an explanation for how an individual's physical and mental health is maintained and promoted. The individual's social support, based on the stress buffering and main effect models, influences the individual's emotions, cognition, and behaviors, and consequently; are able to perceive risk factors and functions in a healthy way to maintain and promote their health. This may resulted in maintaining positive levels of optimism, life satisfaction and effectively using coping skills. The results also support Lewinsohn's model that patients with chronic illnesses are at risk for depression if their illness affected their ability to function [27]. In this study, patients were able to maintain their function utilizing psychological and social support that, in turn; resulted in improving their life satisfaction and optimistic view of their life. In conclusion, Jordanian patients with chronic illness are suffering psychological and social disturbances, however; they were able to manage and maintain their functionability that affected positively their optimistic view of life, their satisfaction about their life and their ability to use effective coping skills.

This study also found that older patients are more likely to have higher level of support from friends and others, higher level of life satisfaction, lower level of support from friends and higher level of psychological distress. Which also corresponds with our previous explanation that chronicity of illness if not disabled patient causing significant dysfunction; it will not worsen their psychological status. Moreover, female patients had higher scores in depression, stress and perceived social support from family. The results agree with previous studies [24] that female patients had higher scores in depression than male patients. However, this study is the first to compare six psychosocial factors among five types of chronic illnesses. This study found that there were significant differences among the five types of chronic illnesses across the six psychosocial factors. Particularly, the study found that patients diagnose with cancer and diabetes mellitus found to be most different than all others patients groups (arthritis, CVD, and pulmonary diseases). The study results also add that depressive symptoms and perceived social support from friends were the most psychosocial factors that seem to be different across the five groups of patients.

One limitation for this study is that data were cross sectional. A longitudinal study may allow better understanding for a cumulative experience over long period of time.

\section{Conclusions}

Psychological disturbances are common in hospitalized patients with chronic illnesses. This study found that although patients had moderate levels of depression and stress, patients also had positive optimistic view of their lives and life satisfaction, able to use effective coping skills, and had positive perceived social support. Sociodemographic factors and type of illness had also found to be significant factors in determining the prevalence of psychosocial levels.

The study has an implication for health professionals at the community and primary care settings. There is a need to assess and screen for psychosocial factors such as stress, depression, social support, optimism, life satis- 
faction and coping skills which are among patients with chronic illness in their routine checkups and visits to outpatients units. There is also a need to develop large treatment trials aimed at improving outcomes of psychosocial wellbeing in medical illnesses to prospect the cost and burden of such illnesses. Sociodemographic factors and type of illness should also be taken into account in planning future studies as well as screening and intervention programs.

\section{References}

[1] Doumit, J. and Nasser, R. (2010) Quality of Life and Wellbeing of the Elderly in Lebanese Nursing Homes. International Journal of Health Care, 23, 72-93.

[2] Sareen, J., Cox, B.J., Clara, I. and Asmundson, G. (2005) The Relationship between Anxiety Disorders and Physical Disorders in the U.S.: National Comorbidity Survey. Depression \& Anxiety, 21, 193-202. http://dx.doi.org/10.1002/da.20072

[3] Harter, M.C., Conway, K.P. and Merikangas, K.R. (2003) Associations between Anxiety Disorders and Physical Illness. European Archive of Psychiatry Clinical Neurosciences, 253, 313-320. http://dx.doi.org/10.1007/s00406-003-0449-y

[4] Katon, W., Lin, E.H. and Kroenke, K. (2007) The Association of Depression and Anxiety with Medical Symptom Burden in Patients with Chronic Medical Illness. General Hospital Psychiatry, 29, 147-155. http://dx.doi.org/10.1016/j.genhosppsych.2006.11.005

[5] Sullivan, M., Simon, G., Spertus, J. and Russo, J. (2002) Depression-Related Costs in Heart Failure Care. Archive of Internal Medicine, 162, 1860-1866. http://dx.doi.org/10.1001/archinte.162.16.1860

[6] Wang, P.S., Demler, O., Olfson, M., Pincus, H.A., Wells, K.B. and Kessler, R.C. (2006) Changing Profiles of Service Sectors Used for Mental Health Care in the United States. The American Journal of Psychiatry, 163, 1187-1198. http://dx.doi.org/10.1176/appi.ajp.163.7.1187

[7] Frasure-Smith, N. and Lespérance, F. (2006) Recent Evidence Linking Coronary Heart Disease and Depression. The Canadian Journal of Psychiatry, 51, 715-730.

[8] Rozanski, A., Blumenthal. J.A., Davidson, K.W., Saab, P.G. and Kubzansky, L. (2005) The Epidemiology, Pathophysiology, and Management of Psychosocial Risk Factors in Cardiac Practice: The Emerging Field of Behavioral Cardiology. Journal of the American College of Cardiology, 45, 637-651. http://dx.doi.org/10.1016/j.jacc.2004.12.005

[9] Chen, P.Y. and Chang, H.C. (2012) The Coping Process of Patients with Cancer. European Journal of Oncology Nursing, 16, 10-16. http://dx.doi.org/10.1016/j.ejon.2011.01.002

[10] MacDonald, B.H. (2001) Quality of Life in Cancer Care: Patients' Experiences and Nurses’ Contribution. European Journal of Oncology Nursing, 5, 32-41. http://dx.doi.org/10.1054/ejon.2000.0118

[11] Zhang, C.X., Chen, Y.M. and Chen, W.Q. (2008) Association of Psychosocial Factors with Anxiety and Depressive Symptoms in Chinese Patients with Type 2 Diabetes. Diabetes Research and Clinical Practice, 79, 523-530. http://dx.doi.org/10.1016/j.diabres.2007.10.014

[12] Brislin, R.W. (1970) Back Translation for the Cross-Cultural Research. Journal of Cross Cultural Research, 1, 185216. http://dx.doi.org/10.1177/135910457000100301

[13] Zimet, G.D., Dahlem, N.W., Zimet, S.G. and Farley, G.K. (1988) The Multidimensional Scale of Perceived Social Support. Journal of Personality Assessment, 52, 30-41. http://dx.doi.org/10.1207/s15327752jpa5201_2

[14] Beck, G., Steer, R. and Brown, G. (1996) Manual for the Beck Depression Inventory-II. Psychological Corporation, San Antonio.

[15] Lemyre, L., Tessier, R. and Eillion, L. (1990) Mesure du Stress Psychotogique (MSP): Manuel d’Utilisation [Psychological Stress Measure]. Editions, Brossard.

[16] Carver, C.S. (1990) You Want to Measure Coping but Your Protocol’s Too Long: Consider the Brief Cope. International Journal of Behavioral Medicine, 4, 92-100. http://dx.doi.org/10.1207/s15327558ijbm0401_6

[17] Scheier, M.F., Carver, C.S. and Bridges, M.W. (1994) Distinguishing Optimism from Neuroticism (and Trait Anxiety, Self-Mastery, and Self-Esteem): A Reevaluation of the Life Orientation Test. Journal of Personality and Social Psychology, 67, 1063-1078. http://dx.doi.org/10.1037/0022-3514.67.6.1063

[18] Diener, E., Emmons, R.A., Larsen, R.J. and Griffin, S. (1985) The Satisfaction with Life Scale. Journal of Personality Assessment, 49, 71-75. http://dx.doi.org/10.1207/s15327752jpa4901_13

[19] Honyashiki, M., Ferri, C.P., Acosta, D., Guerra, M., Huang, Y., Jacob, K.S., et al. (2011) Chronic Diseases among Older People and Co-Resident Psychological Morbidity: A 10/66 Dementia Research Group Population-Based Survey. International Psychogeriatrics, 23, 1489-1501. http://dx.doi.org/10.1017/S1041610211000500

[20] Hamdan-Mansour, A., Halabi, J. and Dawani, H. (2009) Depression, Hostility, and Substance Use among University 
Students in Jordan. Mental Health and Substance Use: Dual Diagnosis, 2, 52-63. http://dx.doi.org/10.1080/17523280802593301

[21] Hamdan-Mansour, A. (2010) Predictors of Hostility among University Students in Jordan. Scandinavian Journal of Caring Sciences, 24, 125-130. http://dx.doi.org/10.1111/j.1471-6712.2009.00695.x

[22] Hamdan-Mansour, A., Al Badawi, T., Marmash, L. and Al-Haourani, E. (2013) Depression, Stress and Coping among Patients Diagnosed with Diabetes Mellitus Type-II. Life Science Journal, 10, 3044-3048.

[23] Anderson, R.J., Freedland, K.E., Clouse, R.E. and Lustman, P.J. (2001) The Prevalence of Comorbid Depression in Adults with Diabetes. Diabetes Care, 24, 1069-1078. http://dx.doi.org/10.2337/diacare.24.6.1069

[24] Freedland, K.E., Rich, M.W., Skala, J.A., Carney, R.M., Dávila-Román, V.G. and Jaffe, A.S. (2003) Prevalence of Depression in Hospitalized Patients with Congestive Heart Failure. Psychosomatic Medicine, 65, 119-128. http://dx.doi.org/10.1097/01.PSY.0000038938.67401.85

[25] Niti, M., Ng, T., Kua, E.H., Ho, R.C.M. and Tan, C.H. (2007) Depression and Chronic Medical Illnesses in Asian Older Adults: The Role of Subjective Health and Functional Status. International Journal of Geriatric Psychiatry, 22, 10871094. http://dx.doi.org/10.1002/gps.1789

[26] Cohen, S., Underwood, L.G. and Gottlieb, B.H. (2000) Social Relationships and Health. In: Cohen, S., Underwood, L.G. and Gottlieb, B.H., Eds., Social Support Measurement and Intervention: A Guide for Health and Social Scientists, Oxford University Press, New York.

[27] Lewinsohn, P.M., Hoberman, H., Teri, L. and Hautzinger, M. (1985) An Integrative Theory of Depression. In: Reiss, S. and Bootzin, R.R., Eds., Theoretical Issues in Behavior Therapy, Academic Press, San Diego, 331-359. 
Scientific Research Publishing (SCIRP) is one of the largest Open Access journal publishers. It is currently publishing more than 200 open access, online, peer-reviewed journals covering a wide range of academic disciplines. SCIRP serves the worldwide academic communities and contributes to the progress and application of science with its publication.

Other selected journals from SCIRP are listed as below. Submit your manuscript to us via either submit@scirp.org or Online Submission Portal.
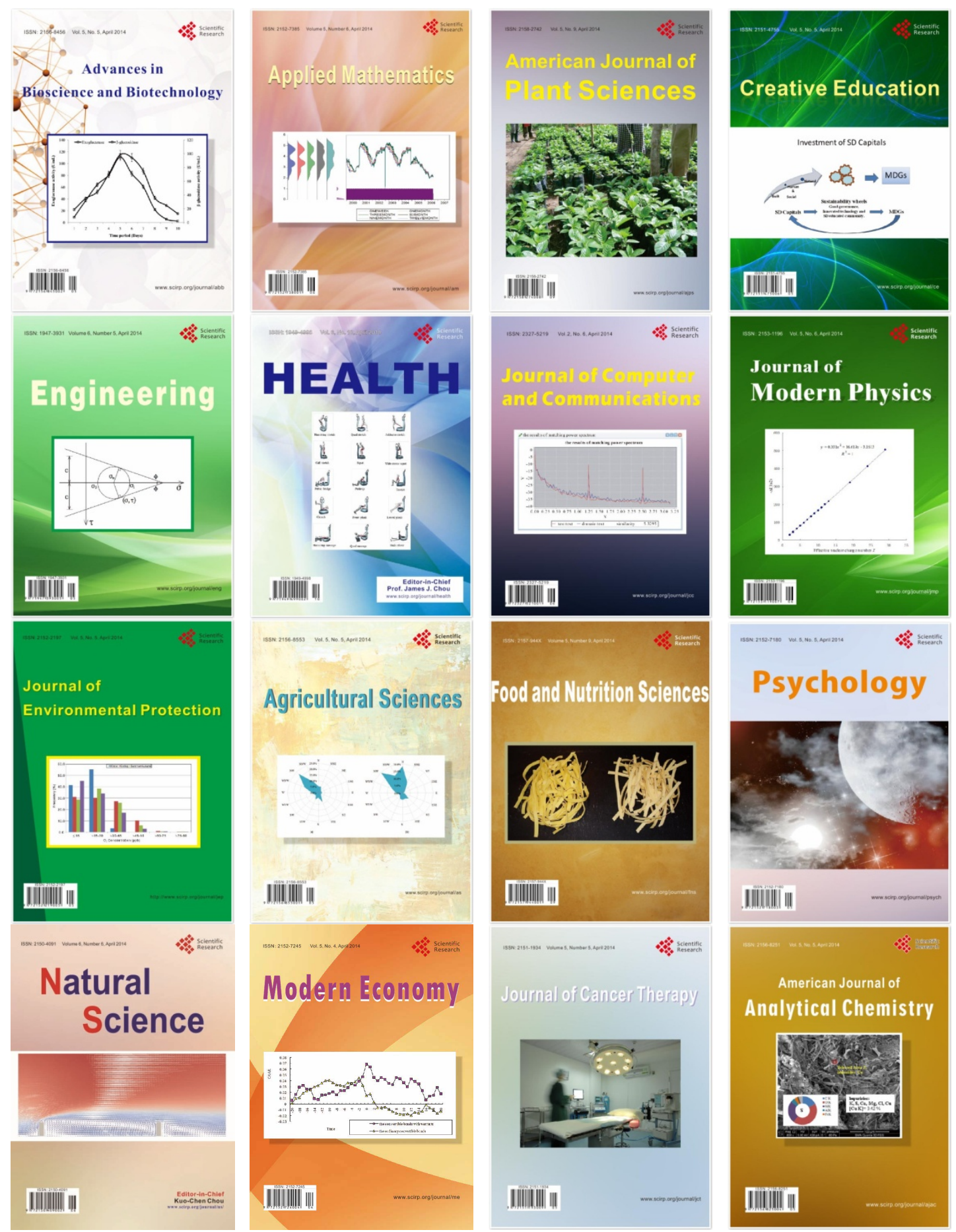